\title{
Brain fag syndrome among Nigerian university students in Abuja
}

\author{
Ifedilichukwu Uzoeghe Uchendu' ${ }^{1}$, Eze Uzoechi Chikezie ${ }^{2^{*}}$ and Olufemi Morakinyo ${ }^{3}$ \\ *Correspondence: ezechikezie@yahoo.com

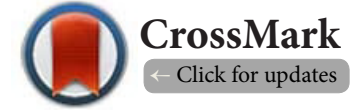 \\ 'Department of Internal Medicine (Psychiatry), University of Abuja Teaching Hospital, Gwagwalada, Abuja (FCT), Nigeria. \\ ${ }^{2}$ Department of Mental Health, Faculty of Clinical Sciences, Niger Delta University, Amassoma, Bayelsa state, Nigeria. \\ ${ }^{3}$ Department of Psychiatry, College of Health Sciences, University of Benin, Benin City, Nigeria.
}

\begin{abstract}
Background: The Brain Fag syndrome is considered to be a culture-bound syndrome. While some authorities view it as a variant of anxiety and somatic disorders, others consider it as a specific psychiatric disorder characterized by somatic and cognitive impairments associated with study. It was first described by Prince among Nigerian students and is rarely seen in Western cultures as so described. Morakinyo has also described this syndrome in details. It is thought to result from imposition of alien Western learning techniques on non-Western students. Despite the challenges in classification, Brain fag syndrome contributes to difficulties experienced by students in their academic pursuit and may lead to discontinuation of education.

Methods: We investigated this syndrome among $3^{\text {rd }}$ and $4^{\text {th }}$ year students from different faculties in the University of Abuja. This was a cross-sectional study in which 600 students were randomly selected to participate. The instruments were made up of a sociodemographic questionnaire, the Brain Fag syndrome scale, the WHO questionnaire for student drug use surveys and the University College London study difficulty questionnaire. Data was analysed using SPSS-16.

Results: Prevalence of Brain Fag syndrome was $36 \%$ and commoner among male students and those who had significant financial difficulties. No association was found with age and family background. Study difficulty was found in $53.8 \%$ of the population. Though no significant association with Brain Fag syndrome in general, 25.7\% of students had both study difficulty and Brain Fag syndrome. Positive lifetime use/abuse of psychoactive substances (especially stimulants) was significantly associated with the diagnosis of Brain Fag syndrome. This was also higher among the male population.

Conclusion: Brain Fag syndrome is now widely accepted as an entity of its own and not just a variant of anxiety/depression. The symptoms of discomfort in the head, poor understanding and poor memory associated with study have been clearly described. These impair study among university students as we found and is made worse by use of stimulants. Consequently, impairments in mental health and academic pursuits are likely to result. These have to be further explored and adequate measures put in place to address resulting challenges.
\end{abstract}

Keywords: Brain fag syndrome, nigeria, university students, psychoactive substances

\section{Introduction}

Reports have shown in literatures that passing examinations is an important means to a better and improved living standard in Nigeria [1]. Much of one's success in examinations depends on the ability to learn and reproduce what was learnt. Students need optimal mental health (successful performance of mental functions in terms of thought, mood and behaviour) to achieve academic success. A report from the Summit on the Initiative for Mental Health stated that "studies indicate that approximately 1 in every 5 undergraduate students in North American schools has significant mental health problems that need attention" [2]. Anxiety disorders were the most common problems diagnosed among College students (41.6\%), followed by Depression (36.4\%) and relationship difficulties (35.8\%) [3]. About $24.5 \%$ of them were on psychotropic medications.

The Brain Fag Syndrome (BFS) is a psychiatric syndrome characterized by somatic complaints, cognitive impairments and sleep related complaints, which is associated with study or intense academic (intellectual) work. Such complaints include unpleasant sensations in the head, difficulties understanding while reading, poor memory, inability to concentrate and visual impairments while studying, amongst others. These symptoms are severe and prevent students from carrying on with study. It was first described by Raymond Prince among Nigerian students in 1960 [4]. He called it Brain Fag Syndrome due the belief by the affected students that their brains were fatigued. Prince postulated that the imposition of Western learning techniques on Nigerian students was mainly responsible for this syndrome. The Western techniques were thought to be orderly and individualistic as against the collective style of learning in Nigerian cultures.

Morakinyo proposed the psycho-physiological theory to further elaborate on the etiology and clinical presentation of this syndrome [5]. The African student's aversion for Western 
Uchendu et al. Journal of Psychiatry and Brain Functions 2014,

education and use of psychostimulants were believed to be a major predisposing factors among others. Morakinyo [6] also described the following clusters of clinical symptoms among African students with BFS:

(a) Intellectual impairments, inability to grasp the meanings of materials being read, poor retention and recall, and difficulty with concentrating while reading.

(b) Unpleasant sensations like heat or burning sensations, pain aches, peppery sensations around the head and neck associated with study; either coming on when the student attempts intellectual activity or may be continuously present but worsens when study is attempted and other sensory disturbances like blurring of vision or just seeing blank.

(c) Fatigue and sleepiness in spite of adequate rest.

(d) Affective disturbances which may not be present or be volunteered by the student, but which may take the form of fear, anxiety and/or depression.

The Diagnostic and Statistical Manual, $4^{\text {th }}$ edition (DSM IV) classified BFS as a culture-bound syndrome [7]. However, it has been debated whether BFS should be considered as an entity on its own or a variant of anxiety/depression. Prince and Morakinyo have argued that Brain fag syndrome is an entity on its own based on the fact that the symptoms are specifically associated with study among African students and students in some other similar non-Western cultures. Though some of the symptoms can be found in depression/anxiety states, the presence of the core symptoms and association to study was unique and deserved a separate classification [8]. In contrast, some have argued that the symptoms of Brain fag syndrome are found in anxiety/depressive states, or that the syndrome is not unique to deserve a separate classification [9].

However, several studies have reported varying prevalence rates of Brain fag syndrome. These range between $22.4 \%$ and $40.2 \%$ among different populations of Nigerian students $[1,10,11]$. A rate of $25 \%$ has been reported among Secondary school students in South Africa [12]. Factors such as nervous predisposition, motivation for achievement and psychostimulant use have been linked to the etiology of BFS $[1,11]$.

The syndrome has been reported in other countries in West Africa, such as, Liberia $[13,14]$ and Cote d'Ivoire [15]. It has also been reported from the other parts of Africa, South of Sahara and in students of African descent who were studying in the Western countries, but is rather rare among Caucasians.

Whatever the etiological or nosological controversies surrounding BFS, it is important that this syndrome be widely investigated and well understood because one of the consequences is early drop out from school and termination of education [1]. Most literatures in Nigeria have come from the South West geopolitical zone and other zones have to be studied also.

Based on this, we conducted this study to investigate the prevalence and factors associated with BFS among University students in the Federal Capital Territory (FCT).

\section{General aim of the study}

The main objective of this study is to determine the prevalence and factors associated with brain fag syndrome among students of the University of Abuja.

\section{Methods}

\section{Location and participants}

The study was conducted at the University of Abuja, MiniCampus, Gwagwalada, Abuja, in the Federal Capital Territory (FCT). The University admits students from the Federal Capital Territory and the 36 states of Nigeria as well as the neighbouring countries. It is relatively new; hence only 6 Faculties are fully developed. Stratified random sampling was used in recruiting 624 participants in the study from the 6 Faculties. Full-time students in their $3^{\text {rd }}$ and $4^{\text {th }}$ year, who gave consent, were selected for the study. Part-time students and those in lower classes were excluded. Part-time students were difficult to reach and we thought those in lower classes were still'settling' into the university system.

Permission was sought and received from the authorities of University of Abuja for the purpose of this study. Written informed consent was obtained from the participating students. It was emphasized that students had the right of refusal to participate in this study. The relevance of the study was also explained to them.

\section{Instruments for data collection}

Data was collected with the following instruments:

Sociodemographic information was collected with a questionnaire developed for that purpose.

The Brain Fag Syndrome Scale was used to diagnose the syndrome among participants. This scale was initially developed by Prince in 1962 [16], but later modified by Prince and Morakinyo [6] who developed it into a 7 item scale. This was done in order to improve its validity for detecting the syndrome. For each item, there are three (3) responses, which are Often, Sometimes, and Never, relating to the presence or absence of symptoms. They assigned scores of 2, 1 and 0 respectively. The maximum score obtainable on the scale ranges from 0 to 14. The higher the score the higher the severity of the illness. The scale is designed to discriminate between "caseness" and "noncaseness". For caseness, two conditions must be satisfied. The respondent must have a minimum score of six (6) which must include a score one on each of items 4 and 5 . These items deal with the presence of bodily symptoms such as crawling sensations or heat in the head and the interference of those bodily symptoms with studying.

The World Health Organization (WHO) Questionnaire for Student Drug use Surveys was used to collect data on current and life-time use of various psychoactive substances among the participants [17].

The University College London Study Difficulty Questionnaire 
was used to assess consolidated study difficulty among participants [18]. This questionnaire was devised by Crown and colleagues in 1973. It was produced after a careful clinical evaluation of complaints of students with study difficulty by the authors. They were specific only on affective and motivational factors contributing to study difficulty excluding socio-cultural and interaction factors. In its original form, UCLSQ consist of 7 subscales. Each scale consists of nine items with 3 possible responses. It was later modified by addition of another subscale bringing the total number to 8 subscales. The three (3) possible responses are mainly True, Neither True nor False and only false, these are assigned scores of 2, 1 and 0 respectively. There are 9 questions for each sub-scale, hence the total score obtainable for each subscale, ranges from 0 to 18 . The following are the sub-scales:

1) Anxiety (ANX)-the higher the score, the higher the level of anxiety.

2) Obsessionality (OBS)-the higher the score the higher the level of Obsessionality.

3) Depression (DEP)-the higher the score the higher the level of depression.

4) Disorganised-distractible (DIS)-the higher the score the higher the level of disorganisation/distractibility.

5) Low motivation (L-MOT)-the higher the score the lower the level of motivation.

6) Somatic (SOM)-the higher the score, the higher the level of somatization.

7) Work satisfaction (W-SAT)-the higher the score the higher the level of satisfaction at work (i.e., low score implies low satisfaction).

8) Sylbism (SYL)-the higher the score the higher the level of sylbism or syllabus boundness. This was the later addition (Lucas et al., 1976). With this addition, the items were arranged so that Anxiety items are Numbers 1, 9, 17, 25 etc. Obsessionality items are Nos 10, 18, 26 etc, with the other subscales following similar sequence on the instrument. The authors reported satisfactory reliability and validity.

For this study the median scores of each of the eight subscales would be chosen as the cut off point. The respondents with the scores above the median score for each subscale will be classified as positive and those with scores below the median scores would be termed negative for the subscales respectively. To identify the respondents positive for study difficulty, the median score of the total scores of the respondents in all the subscale will chosen as the cut off point. The respondents with total scores (overall scores) above the median would be classified as positive for consolidated study difficulty, while those with total scores (overall scores) less than the median would be termed negative for consolidated study difficulty.

These instruments have been used in previous studies $[1,10,11]$ and are self-administered.

Two research assistants were employed and trained by the lead author to assist in distributing the instruments and rendering necessary assistants to participants. These assistants were newly-graduated medical doctors awaiting placement for internship. They were trained by Uchendu IU (the lead author) on how to administer the research instruments and relate with students for that purpose. This helped in shortening period of data collection and improve quality of data. The instruments were pre-tested prior to commencement of the study.

Data so obtained were analysed using the Statistical Package for Social Sciences version 16 (SPSS-16) with relevant tests of significance where applicable. Significance was accepted at $p<0.05$.

\section{Results}

A total of 624 questionnaires were administered to the participants. Sixteen (16) questionnaires were rejected due to non-completion, and eight (8) due to inconsistent and conflicting data. Six hundred (600) questionnaires were finally analysed giving a response rate of $96.2 \%$. The males were $295(49.5 \%)$ while females were $305(50.8 \%)$. Their ages ranged between 18-41 years with a total average age of 23.2 \pm 3.39 years. The mean age of males was 23.98 years while that of females was 22.45 years. The males were significantly older ( $t=5.52, p<0.003)$. Most of the participants (93.9\%) were within ages 18 and 29 years. Christianity was the most common religion (74.5\%) and most of the respondents (31.5\%) were from the North Central geopolitical zone and the FCT. The participants were mostly from monogamous homes (71.8\%) and homes in which family relationships are stable and cordial (94.3\%). 5.7\% were from dysfunctional homes. Five hundred and ninety-three (98.8\%) were single or never married. A greater percentage (61.9\%) of the respondents fathers had tertiary education compared with their mothers $(56.8 \%)$. More of the mothers (10.4\%) had no formal education in comparison with their fathers (8.2\%).

Most of the respondents' parents belonged to the first five groups of occupations namely Legislators, Senior Officials, Managers; Professionals, Technicians; Clerical Officers and Sales Business and Services related workers. This implies that most of them were from the middle and upper classes of the society. The sociodemographic information of participants are shown in (Table 1).

Score of 6 and above and minimum of one score in items 4 and 5 was used as criteria for caseness. Based on this, 216(36\%) of participants met criteria for Brain Fag syndrome. These were made up of $121(20.2 \%)$ males and $95(15.8 \%)$ females. Brain Fag syndrome was significantly higher among males ( $p=0.024$ ). The mean score was $5.19 \pm 0.08$, with males scoring higher $(t=3.70, p=0.003)$. Brain Fag syndrome was found to be associated with financial constraints such as difficulties with payment of school fees and other levies. There was no association between Brain Fag syndrome and participants' age group, marital status, geopolitical origin, religion, Faculty and year of study, family background or relationship. One hundred and forty-five (24.2\%) participants who were diagnosed with 
Uchendu et al. Journal of Psychiatry and Brain Functions 2014,

Table 1. Sociodemographic variables.

\begin{tabular}{|c|c|c|c|}
\hline Variable & & Number (n) & $\%$ \\
\hline \multirow[t]{2}{*}{ Gender } & Male & 295 & 49.2 \\
\hline & Female & 305 & 50.8 \\
\hline \multirow[t]{4}{*}{ Age group (In years) } & $18-23$ & 277 & 46.1 \\
\hline & $24-29$ & 287 & 47.8 \\
\hline & $30-35$ & 26 & 4.4 \\
\hline & $36-41$ & 10 & 1.7 \\
\hline \multirow[t]{3}{*}{ Religion } & Christianity & 447 & 74.5 \\
\hline & Islam & 141 & 23.5 \\
\hline & Others & 12 & 2.0 \\
\hline \multirow[t]{6}{*}{ Geopolitical zone } & $\mathrm{NC}+\mathrm{FCT}$ & 189 & 31.5 \\
\hline & $\mathrm{NE}$ & 28 & 4.7 \\
\hline & NW & 54 & 9.0 \\
\hline & SE & 126 & 21.0 \\
\hline & SW & 85 & 14.2 \\
\hline & SS & 118 & 19.7 \\
\hline \multirow[t]{5}{*}{ Marital status } & Single & 593 & 98.8 \\
\hline & Married & 5 & 0.8 \\
\hline & Divorced/separated & 1 & 0.2 \\
\hline & Widow/widower & 0 & 0 \\
\hline & Others & 1 & 0.2 \\
\hline \multicolumn{4}{|l|}{ Family background } \\
\hline \multirow[t]{5}{*}{ Father's education } & Primary & 60 & 10.2 \\
\hline & Secondary & 93 & 15.8 \\
\hline & Tertiary & 364 & 61.9 \\
\hline & No formal education & 50 & 8.5 \\
\hline & Don't know & 3.6 & 3.6 \\
\hline \multirow[t]{5}{*}{ Mother's education } & Primary & 73 & 12.5 \\
\hline & Secondary & 91 & 15.5 \\
\hline & Tertiary & 333 & 56.8 \\
\hline & No formal education & 61 & 10.4 \\
\hline & Don't know & 26 & 4.8 \\
\hline \multirow[t]{2}{*}{ Father's occupation } & Groups 1-5 & 442 & 73.6 \\
\hline & Other groups & 158 & 26.4 \\
\hline \multirow[t]{2}{*}{ Family setting } & Monogamous & 431 & 71.8 \\
\hline & Polygamous & 169 & 38.2 \\
\hline \multirow[t]{4}{*}{ Family relationship } & $\begin{array}{l}\text { Parents separated/ } \\
\text { divorced/dead parent(s) }\end{array}$ & 22 & 3.7 \\
\hline & Friendly/cordial & 559 & 93.2 \\
\hline & Not friendly & 12 & 2.0 \\
\hline & Missing data & 7 & 1.1 \\
\hline \multirow[t]{4}{*}{ Financial constraints } & Frequent & 222 & 37.0 \\
\hline & Seldom & 77 & 12.8 \\
\hline & Never & 282 & 47.0 \\
\hline & Missing data & 19 & 3.2 \\
\hline
\end{tabular}

NC: North Central, NE: North East, NW: North West, SE: South East, SW: South West, SS: South South
Brain Fag syndrome also met criteria for lifetime use/abuse of psychoactive substances. Stimulants (coffee and kolanuts), alcohol, tobacco, and cannabis were psychoactive substances most commonly used by them. Males are more likely to use psychoactive substances and develop Brain Fag syndrome than females (OR 3.8). Study difficulty was found among $323(53.8 \%)$ participants out of which $154(25.7 \%)$ also had Brain Fag syndrome. Study difficulty was significantly higher among males with Brain Fag syndrome than corresponding females ( $P=0.014)$. (Tables 2 and 3 ).

\section{Discussion}

There were more females than males in the study population, male: female (M: F) ratio is 1:1.03. This is comparable to the general population of the students of University of Abuja with male: female ratio (M: $F$ ) of 1:1.05. This differed from other studies where male dominance was reported in tertiary institutions $[19,20]$. The preponderance of female gender in this study could reflect the admission policy of the university and the sampling methodology which captured males and females based on equal chances.

The age of the respondents ranged between 18 and 41 years, this is similar to age range (16-43 years) reported by Daramola [19]. As expected, majority of the participants were single, young persons.

The level of education and occupation of the participant's father was used as a crude indicator of the social class as was previously used [21]. Based on this, more than half of participants belonged to the upper and middle classes. Onofa [20] however, reported higher preponderance of respondents

Table 2. Brain Fag syndrome (BFS) and other related features.

\begin{tabular}{|c|c|c|c|c|}
\hline Feature & & Number(n) & $\%$ & Level of significance \\
\hline \multicolumn{5}{|c|}{$\begin{array}{l}\text { Brain Fag } \\
\text { syndrome }\end{array}$} \\
\hline \multirow[t]{2}{*}{ Present } & Males & 121 & 20.2 & 0.024 \\
\hline & Females & 95 & 15.8 & -- \\
\hline \multirow[t]{2}{*}{ Absent } & Males & 174 & 29.0 & -- \\
\hline & Females & 210 & 35.0 & -- \\
\hline \multicolumn{5}{|c|}{$\begin{array}{l}\text { Lifetime } \\
\text { psychoactive } \\
\text { substance use }\end{array}$} \\
\hline & Yes & 406 & 67.7 & 0.016 \\
\hline & No & 194 & 32.3 & -- \\
\hline \multicolumn{5}{|c|}{$\begin{array}{l}\text { Study difficulty } \\
\text { (total population) }\end{array}$} \\
\hline Present & -- & 323 & 53.8 & 0.062 \\
\hline Absent & -- & 277 & 46.2 & -- \\
\hline \multicolumn{5}{|c|}{$\begin{array}{l}\text { Study difficulty } \\
\text { (BFS cohort) }\end{array}$} \\
\hline Present & -- & 154 & 71.3 & -- \\
\hline Absent & -- & 62 & 28.7 & -- \\
\hline
\end{tabular}


Table 3. Relationship between the BFS \& psychoactive substances.

\begin{tabular}{|c|c|c|c|c|}
\hline \multirow{2}{*}{$\begin{array}{l}\text { Psychoactive } \\
\text { substance (lifetime) } \\
\text { use }\end{array}$} & \multicolumn{2}{|c|}{ BFS N-216 } & \multirow{2}{*}{$\begin{array}{l}\text { P value } \\
\text { Fishers Exact } \\
\text { Test }\end{array}$} & \multirow{2}{*}{$\begin{array}{l}\text { Odd Ratio } \\
\text { (OR) }\end{array}$} \\
\hline & Yes & $\%$ & & \\
\hline Tobacco $(\mathrm{n}=144)$ & 83 & 38.4 & $<0.001^{*}$ & 3.3 \\
\hline Alcohol $(\mathrm{n}=344)$ & 158 & 73.1 & $<0.001^{*}$ & 3.1 \\
\hline Cannabis $(\mathrm{n}=87$ ) & 56 & 25.9 & $<0.001^{*}$ & 3.9 \\
\hline Cocaine $(\mathrm{n}=29)$ & 17 & 7.9 & $<0.05^{* *}$ & 2.6 \\
\hline Stimulants $(\mathrm{n}=214)$ & 117 & 54.7 & $<0.001^{*}$ & 4.5 \\
\hline Hallucinogens $(\mathrm{n}=22)$ & 12 & 5.6 & $>0.05^{\star * *}$ & 1.0 \\
\hline Inhalants $(\mathrm{n}=67)$ & 40 & 18.5 & $<0.001^{*}$ & 2.0 \\
\hline Tranquillizers $(\mathrm{n}=35)$ & 21 & 9.7 & $<0.05^{* *}$ & 1.8 \\
\hline Barbiturates $(\mathrm{n}=10)$ & 8 & 3.7 & $<0.05^{\star *}$ & 1.3 \\
\hline Opium $(\mathrm{n}=10)$ & 6 & 1.0 & $>0.05^{\star * *}$ & 0.7 \\
\hline Heroin $(\mathrm{n}=10)$ & 8 & 3.7 & $>0.05^{* * *}$ & 0.3 \\
\hline Other opiates $(\mathrm{n}=17)$ & 11 & 6.1 & $>0.05^{* * *}$ & 0.3 \\
\hline
\end{tabular}

Key:

${ }^{\star}$ Highly significant $(\mathrm{p}<0.001)$.

${ }^{*}$ Moderately significant $(\mathrm{p}<0.05)$.

${ }^{* * *}$ Not significant $(\mathrm{p}>0.05)$.

in the low social class in a study among University students. The study locations could account for these differences.

The prevalence of Brain Fag syndrome is $36 \%$. This is higher than the $22.9 \%$ reported among Secondary school students by Fatoye [10]. This may be due to the higher degrees of academic and other challenges confronted by University students. Other studies had reported rates of 22.4 to $40.2 \%$ among secondary school students $[\mathbf{1}, \mathbf{1 1}, 12]$. Differences in degrees of westernization have been suggested as possible reasons for these disparities. Brain Fag syndrome was found to be commoner among males who are more likely to use psychoactive substances which will predispose them to developing the syndrome. This was also reported by Fatoye [22]. However, other studies did not find any relationship between gender and Brain Fag syndrome $[12,23,24]$. The differences in the samples studied may account for these different observations. There is need to further investigate it. About $67 \%$ of those with Brain Fag syndrome also met criteria for lifetime use/abuse of psychoactive substances, mostly males. The most commonly used substances being stimulants (especially coffee and kolanuts), alcohol, tobacco and cannabis. Use of stimulants was found to be mostly associated with Brain Fag syndrome in a previous study [22] and appear to reinforce the Psycho-Physiological Theory of Brain Fag syndrome which linked stimulants' use to development of Brain Fag syndrome among African students [5]. Financial constraints, such as difficulties with payment of tuition fees and other levies, were also significantly associated with the Brain Fag syndrome. Such constraints are expected to add to stress which these students face daily and subsequently affect them negatively if prolonged. Brain Fag syndrome had been found to be commoner among those in the low socioeconomic class $[5,16,22]$. Surprisingly, no association was found between age, year of study and family relationship with the Brain Fag syndrome. One would have thought that a dysfunctional family relationship could predispose to Brain Fag syndrome. Other literatures have also reported similar observations $[\mathbf{1 , 5 , 1 6}]$. In this study only $5.7 \%$ of participants reported dysfunctional family backgrounds. This fraction may be too small to observe any significant relationship.

Study difficulty was found among $53.8 \%$ of the participants and 154 of them also had Brain Fag syndrome. There was no significant difference in the rates of study difficulty between those students who had Brain Fag and those who did not. This appears to contrast with other studies $[10,22]$ and could have arisen out of differences in methodology and study populations. Although no significant difference was found in the rates of study difficulty among those who had Brain Fag syndrome and those who did not, study difficulty was still very high among those who had Brain Fag syndrome, especially the males. These suggest that male students were more likely to use psychoactive substances, have difficulties with studies and develop Brain Fag syndrome than corresponding females. Associated with this is the common use of coffee and kolanuts by students in this environment to enable them keep awake, study and memorize academic topics just before and during examinations.

This study is one of very few of such among students in tertiary institutions in Nigeria; thus, its location may not necessarily reflect the average picture among university students in general. However, it will serve as a basis for further and larger studies in tertiary institutions that will throw more light on the issues discussed.

\section{Conclusion}

University students face constant challenges in their quest for knowledge that will improve their lives in future. These challenges predispose them to mental health problems which will threaten the whole essence of university education $a b$ initio. The Brain fag syndrome, diagnosed using the Brain fag syndrome scale, was found to be high among our study population. Significant association with stimulant use was also found. These factors and associations have to be further investigated and mental health services introduced and strengthened to meet these needs of Nigerian university students. The introduction of collective learning systems may be of some benefit. The importance of continuous health education as part of these services, especially on the health risks of substance abuse among other factors, cannot be over-emphasized.

\section{Competing interests}

The authors declare that they have no competing interests. 
Uchendu et al. Journal of Psychiatry and Brain Functions 2014, http://www.hoajonline.com/journals/pdf/2055-3447-1-1.pdf

Authors' contributions

\begin{tabular}{|l|c|c|c|}
\hline Authors' contributions & UIU & CUE & MO \\
\hline Research concept and design & $\checkmark$ & $\checkmark$ & -- \\
\hline Collection and/or assembly of data & $\checkmark$ & -- & -- \\
\hline Data analysis and interpretation & - & $\checkmark$ & -- \\
\hline Writing the article & -- & $\checkmark$ & -- \\
\hline Critical revision of the article & -- & -- & $\checkmark$ \\
\hline Final approval of article & $\checkmark$ & $\checkmark$ & $\checkmark$ \\
\hline Statistical analysis & $\checkmark$ & $\checkmark$ & $\checkmark$ \\
\hline
\end{tabular}

\section{Acknowledgement}

The authors wish to thank all participants and the authorities of the University of Abuja for their roles in making this study possible. We also thank the research assistants for helping with the administration of the instruments.

\section{Publication history}

Senior Editor: Gianluca Serafini, Sapienza University of Rome, Italy. Received: 21-Nov-2013 Revised: 27-Jan-2014

Re-Revised: 19-Feb-2014 Accepted: 28-Feb-2014

Published: 21-Mar-2014

\section{References}

1. Ola BA and Morakinyo O. Study habits among Nigerian secondary school students with brain fag syndrome. Mental IIIness. 2010; 2:1 . | Article

2. Report from the Summit on: The Maternal and Child Health Bureau's Initiative for Mental Health in Schools. 1998. I Pdf

3. American Psychological Association. College students' mental health is a growing concern. Monitor on Psychology. 2013; 44:6. | Website

4. Prince R. The "brain fag" syndrome in Nigerian students. J Ment Sci. 1960; 106:559-70. | Article | PubMed

5. Morakinyo O. A psychophysiological theory of a psychiatric illness (the brain fag syndrome) associated with study among Africans. J Nerv Ment Dis. 1980; 168:84-9. | Article | PubMed

6. Morakinyo O. Students' mental health in Africa: present status and future prospects. $15^{\text {th }}$ Annual lecture of the West African College of Physicians, Accra, Ghana. 1990.

7. American Psychiatric Association, Diagnostic and Statistical Manual of Mental Disorders, $4^{\text {th }}$ Edition. Washington, DC. 1994.

8. Peltzer K. Brain fag symptoms among black South African university students. Southern African Journal of Child and Adolescent Mental Health. 2002; 14:115-122. | Article

9. Ayorinde O. Brain fag syndrome: New wine in old bottles or old wine in new bottles? Nigerian J Psychiatry. 2008; 6: 47-50. | Article

10. Fatoye FO and Morakinyo O. Study difficulty and the "Brain Fag" syndrome in South Western Nigeria. J Psychol Africa. 2003; 13:70-80.

11. Eegunranti $A B$. Stimulant use and psychopathology among secondary school students in Osogbo, Osun state, Nigeria. Dissertation submitted to the National Postgraduate Medical College of Nigeria, Faculty of Psychiatry. 2006.

12. Peltzer K, Cherian VI and Cherian L. Brain fag symptoms in rural South African secondary school pupils. Psychol Rep. 1998; 83:1187-96. | Article I PubMed

13. Wintrob RM. The cultural dynamics of student anxiety: A report from Liberia. In Boroffka A, eds. Report on Seminar/Workshop on Psychiatry and Mental Health Care in General Practice. Ibadan. 1971.

14. Thebaud $E$ and Rigamer EF. Some considerations on student mental health in Liberia. African Journal of Psychiatry. 1976; 1:227-232.

15. Lehmann JP. Le vecu corporel et ses interpretations en pathologie africaine a propos des inhibitions intellectuelles en milieu scolaire,
(The somatic sensations and their interpretation in regard of African pathology; considering the intellectual inhibitions in school). Rev Med Psychosom Psychol Med. 1972; 1:43-67.

16. Prince RH. Functional symptoms associated with study among Nigerian students. W Afr Med J. 1962; 11:198-206. | PubMed

17. WHO Questionnaire for Student Drug Use Surveys 2010. | Pdf

18. Crown S, Lucas $\mathrm{CJ}$ and Supramaniam $\mathrm{S}$. The delineation and measurement of study difficulty in university students. $\mathrm{Br} J$ Psychiatry. 1973; 123:381-93. | Article | PubMed

19. Daramola TO. Psychoactive substance use among medical students in University of Ilorin. A Dissertation submitted to the National Postgraduate Medical College of Nigeria, Faculty of Psychiatry. 2004.

20. Onofa L. Prevalence and pattern of drug abuse among students of three tertiary institutions in Abeokuta. A Dissertation submitted to the West African College of Physicians, Faculty of Psychiatry, 2006.

21. Okogbenin EO. Prevalence and correlates of alcohol use/abuse among adolescent secondary school students in Benin City. A Dissertation submitted to the West African College of Physicians, Faculty of Psychiatry. 2008.

22. Fatoye FO. Co-occurrence of study difficulty, drug use and psychopathology among secondary school students in llesha, Western Nigeria. A Dissertation submitted to the National Postgraduate Medical College of Nigeria, Faculty of Psychiatry. 1998.

23. Prince RH. Brain Fag symptoms in Nigerian university students of language and medicine. Psychopathol Afr. 1983; 32: 207-211.

24. Guinness EA. Profile and prevalence of the brain fag syndrome: psychiatric morbidity in school populations in Africa. Br J Psychiatry Suppl. 1992; 42-52. | PubMed

\section{Citation:}

Uchendu IU, Chikezie EU and Morakinyo O.

Brain fag syndrome among Nigerian university students in Abuja. J Psychiatry Brain Funct. 2014; $1: 1$.

http://dx.doi.org/10.7243/2055-3447-1-1 